\section{EVALUATION OF DISINFECTANTS}

A $T$ the British Pharmaceutical Conference, held $A$ at Harrogate during September 10-14, the chairman, Prof. H. Berry, in his address entitled "A Review of Disinfectants and Disinfection", emphasized the importance of disinfection both to the public health and to pharmaceutical practice. This subject, he said, is studied in all its aspects only in schools of pharmacy, and the modern pharmacist should be qualified to give expert advice on disinfectants and to evaluate commercial claims made for them; he should be proof against "high-powered sales talk" about them. In his address, Prof. Berry discussed with refreshing vigour the question of what constitutes a good disinfectant. Controversy about evaluation of disinfectants revolves, he said, around the type of test represented by the Rideal-Walker test and its product, the so-called phenol-coefficient. This biological test is still misunderstood and is often "misused in advertisements to gull the uninformed layman", but it has turned useless disinfectants off the market. Prof. Berry discussed its defects and explained why he considers that it is a badly designed test which "cannot by any stretch of the imagination be translated into terms of therapeutic activity or practical applicability or utility". Some disinfectants, such as 'Lysol', cotrimide and acriflavine, do not need a biolog. ical test ; they can be, and are, controlled by chemical or physico-chemical specifications, such as those that are given in the British Pharmacopoia and its Codex.

The real problem, however, is the evaluation of the utility of a disinfectant after it has been standardized. For this the results of many diverse tests are required, and Prof. Berry discussed these. In Great Britain there is no official body which will adjudicate on new disinfectants, nor is the existing legislation for the control of claims made for them effective, although many of the British Dominions and the United States have attempted their legislative control. Prof. Berry commended, however, the Medical Research Council's valuable Memoir No. 11, entitled "The Control of Cross-Infection in Hospitals" (revised edition; pp. 49 ; London : H.M. Stationery Office, $1951 ; 1 s .9 d$. net), which gives in its Appendix A advice to hospitals on the dis. infectants to be used for various purposes; he expressed the hope that the Ministry of Health will adopt a similar method of dealing with disinfectants on the open market.

The remainder of Prof. Berry's address was devoted to a useful discussion of the valuable properties, and also the limitations, of the quaternary ammonium compounds, which are challenging, in certain fields of use, some of the established disinfectants. The address concluded with a brief, but interesting, account of the discovery that some substances which were believed to kill micro-organisms quickly do not, in fact, kill them, but merely inhibit them, so that they can be revived by treatment with 'revivors', among which are ammonium sulphide and certain thiol compounds. Substances have been found which will revive organisms treated with iodine, hypochlorites and formaldehyde, but none is yet known that will revive organisms treated with phenol. Certain thiol compounds, such as glutathione, occur naturally in the body, and there is evidence that, if pathogenic organisms treated with mercury compounds are injected into the body, they may be revived and may become infective. The evaluation of disinfectants must take account of developments of this kind. Revivors can be used to find out whether disinfectants have, in fact, killed organisms.

In conclusion, Prof. Berry urged that the older disinfectants should not be lightly given up. The hypochlorites are, he said, very valuable, and he had great confidence in the phenolic preparations, 'Lysol', 'Black Fluid' and 'White Fluid', the wide non-specific action of which makes them very reliable. He made a special plea for 'Lysol', but added that the hospitals do need a non-toxic, non-irritating phenol preparation the other properties of which are not inferior to those of 'Lysol'.

\section{CARNEGIE UNITED KINGDOM TRUST}

HE thirty-seventh annual report of the Carnegie United Kingdom Trust, $1950^{*}$, covers the completion of the Trust's first post-war quinquennium, and by the end of the year the grand total of grant payments by the Trustees had reached $£ 4,065,555$. During its thirty-seven years, the Trustees have thus been able to distribute to beneficiaries more than twice the amount of the original endowment of the Trust of $£ 2$ million, and at the same time to increase the income from the original $£ 100,000$ a year to rather more than $£ 130,000$. More than a third of the total expenditure has been on the development of library services which, as explained in last year's report, will now continue without further financial assistance from the Trustees. Nearly $£ 250,000$ has been devoted to playing-fields, mostly within the period 1926-40; but the combined effect of the Physical Training and Recreation Act of 1937 and the Education Acts of 1944 has been to place responsibility in this matter on the local education authorities. Under the same Acts, central and local authorities are now responsible for grants to village halls, to which, if all outstanding promises are taken up in full, the Trust has contributed more than $£ 180,000$.

More than $£ 150,000$ has been provided for community centres and the like, and about $£ 110,000$ on schemes of land settlement, operated by the Land Settlement Association, which, under the Agriculture Act of 1947, is now responsible to the Ministry of Agriculture. Some $£ 450,000$ has been provided for youth services and nearly $£ 50,000$ for the development of museum services, while on the Bureau of Current Affairs, now to be terminated, $£ 123,344$ has been expended. While the Bureau has not been able to establish itself as a self-supporting institution, the Trustees state that they do not regret having made the experiment to find out whether a method that had proved outstandingly successful during the War could be made economically self-supporting in time of peace. The Trustees also terminated at the end of 1950 their support of youth hostels, but the allocation to the National Federation of Young Farmers' Clubs is being spread over six years, instead of the five years originally contemplated. An in. dividual survey on behalf of the Trust is now being undertaken by Mr. John Mack, Stevenson lecturer in citizenship in the University of Glasgow, of agencies and activities concerned with juvenile delinquency, with the object of directing attention to any gaps which might be filled by the action of either statutory or voluntary bodies in furthering existing schemes or initiating new ones.

* Carnegie United Kingdom Trust. Thirty-seventh Annual Report. 